\title{
Optimum Design Criteria for Maximum Torque Density and Minimum Torque Ripple of Flux Switching Motor using Response Surface Methodology
}

\author{
Jung Ho Lee* and Tae Hoon Lee \\ Department of Electrical Engineering, Hanbat National University, Daejeon 305-719, Korea
}

(Received 17 February 2010, Received in final form 17 May 2010, Accepted 19 May 2010)

\begin{abstract}
This paper deals with optimum design criteria for maximum torque density $\&$ minimum torque ripple of a Flux Switching Motor (FSM) using response surface methodology (RSM) \& finite element method (FEM). The focus of this paper is to find a design solution through the comparison of torque density and torque ripple which vary with rotor shape. And then, a central composite design (CCD) mixed resolution was introduced and analysis of variance (ANOVA) was conducted to determine the significance of the fitted regression model. The proposed procedure allows one to define the rotor dimensions, starting from an existing motor or a preliminary design.
\end{abstract}

Keywords : FEM, RSM, FSM, torque density/ripple, optimum design

\section{Introduction}

The flux switching motor (FSM) is a new class of electric motor and is a combination of the switched reluctance motor and the inductor alternator [1,2].

The FSM has a salient pole rotor and may have a salient or non-salient stator.

The stator winding comprises a field winding and armature winding, each spanning a full rotor pole pitch. The field winding carries DC current and the armature winding carries AC current.

The unique benefit of the inductor alternator and the proposed flux switching motor is that one of the two windings can carry DC current leaving only one winding requiring electronic control. The FSM has the potential to be extremely low cost in high volume applications.

Furthermore, being an electronically commutated brushless motor, it inherently offers longer life and very flexible and precise control of torque, speed, and position at no additional cost.

Issues such as torque density and, spatially, torque ripples are important in evaluating the performance of a FSM.

Such characteristics depend upon the stator and rotor shapes of machine and, therefore, require a numerical

*Corresponding author: Tel: +82-42-821-1098

Fax: +82-42-821-1088, e-mail: limotor@hanbat.ac.kr evaluation and design.

Ed-highlight-Is this what you meant? It is odd as a comma splice; if it is appropriate, it may be better to write "spatial torque ripples"

This paper deals with optimum design criteria for maximum torque density \& minimum torque ripple of the FSM using RSM \& FEM.

The focus of this paper is to find a design solution through the comparison of torque density and torque ripple caused by rotor shape variations.

The RSM has been developed to use the experimental design method in combination with FEM and is well adapted to make analytical models for a complex problem with many interactions between the design variables $[3,4]$.

\section{Design Algorithm and Model}

\subsection{Operation principle of the proposed FSM}

Fig. 1 shows the operation principle of the proposed FSM.

Excitation current is constantly supplied to both the field and armature windings throughout the operation of the motor for either rotor alignment position.

The field winding is excited constantly with unipolar direct current that does not require switching.

The switching of the current direction in the armature winding controls the orientation of the resultant stator flux and therefore to which stator poles the rotor is attracted. 


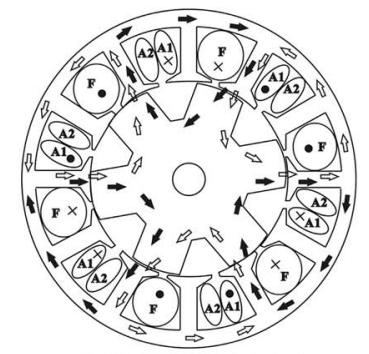

(a1) $\mathrm{F}(+), \mathrm{Al}(+)$

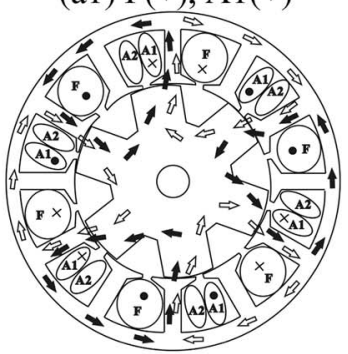

(a2) $\mathrm{F}(+), \mathrm{A} 1(+)$

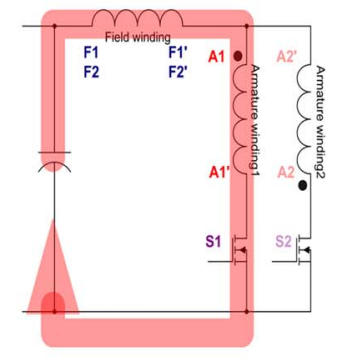

(a3) Drive composition

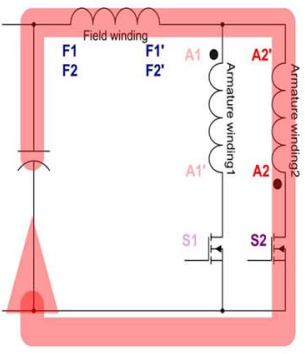

(b3)
Fig. 1. Operation principle of the proposed FSM.

\subsection{Design algorism and initial model}

Fig. 2 shows the point variables and variation direction example for the shape change according to the width and edge of the salient pole.

Each pair of W1-W2 move symmetrically as salient pole width varies. In order to change the shape of the salient pole edge, the points of P1 and P2 are moved to arc directions.

The shape coordinates of the rotor have been drawn according to the variation of the salient pole width and the salient pole edge. Design variables of the rotor are determined to maximize torque density and to minimize torque ripple of a FSM. Then, analysis data is obtained by FEM based on a central composite design mostly used in
RSM.

\subsection{Response surface methodology}

It is always necessary to examine the fitted model to ensure that it provides an adequate approximation to the true response and to verify that none of the least squares regression assumptions are violated. In order to confirm adequacy of the fitted model, analysis-of-variance (ANOVA) table, shown in Table 1, is used in this paper.

In Table $1, n$ is the total number of experiments and $k$ is the number of parameters in the fitted model.

\subsection{Optimization procedure}

Fig. 3 shows the process of optimization design.

The shape coordinates of the rotor have been drawn according to the variation of the salient pole width and the salient pole edge.

The design procedure according to the flow chart is as follows;

Step 1: Set the initial value (CAD file, Pre-processor data). The initial model is assigned to Salient pole $=6$, slot $=12$.

Step 2: Salient pole width (X1) and salient pole edge (X2) in rotor are adopted the design variables related to torque density in the FSM.

Ed-highlight-I am confused by this passage. I would recommend changing it to "... in the rotor adopted the design variables related to torque density in the FSM." Please check to make sure this captures your intended message.

Step 3: The range of design variables and experiment frequency is established by using the central composite

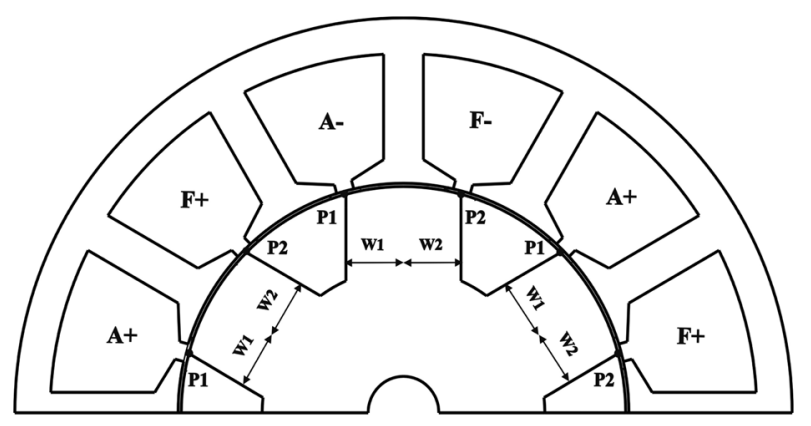

Fig. 2. The design variables and variation direction of the initial model.

Table 1. Analysis of variance.

\begin{tabular}{ccccc}
\hline \hline Source of Variation & Degree of Freedom & Sum of Squares & Mean Square & $F_{0}$ \\
\hline Regression & $\mathrm{k}$ & $\mathrm{SS}_{\mathrm{R}}$ & $\mathrm{SS}_{\mathrm{R}} / k=M \mathrm{~S}_{\mathrm{R}}$ & $M \mathrm{~S}_{\mathrm{R}} / M \mathrm{~S}_{\mathrm{E}}$ \\
Residual & $n-k-1$ & $\mathrm{SS}_{\mathrm{E}}$ & $\mathrm{SS}_{\mathrm{E} /(\mathrm{n}-\mathrm{k}-\mathrm{l})}=M \mathrm{~S}_{\mathrm{E}}$ & \\
Total & $n-1$ & $\mathrm{~S}_{\mathrm{yy}}$ & & \\
\hline
\end{tabular}




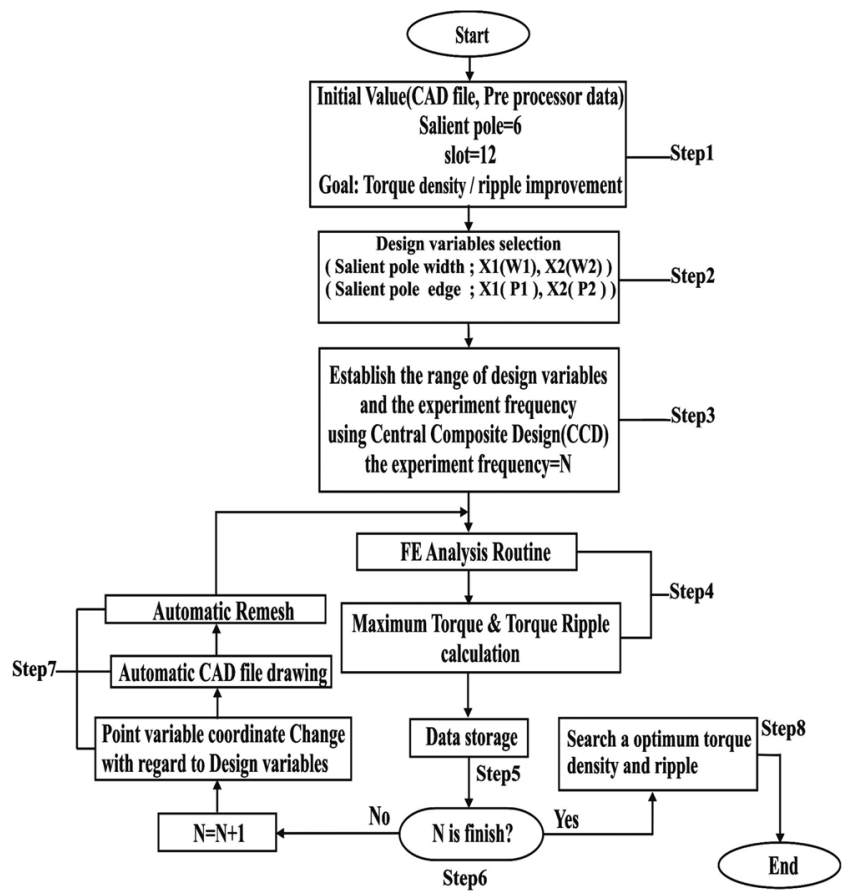

Fig. 3. Flow chart of design procedure.

design $(\mathrm{CCD})$. The experiment frequency $(\mathrm{N})$ is 25 .

Step 4: Finite element analysis (FEA) is performed and torque density and torque ripple are calculated.

Step 5: The torque density and ripple obtained from FEA are stored.

Step 6: The experiment frequency $\mathrm{N}>25$ ?

- Yes: Search for an optimum torque density and ripple.

No: $\mathrm{N}=\mathrm{N}+1$

Step 7: The example of the point variables and variation direction of the salient pole width and the salient pole edge is shown in Fig. 2.

When the rotor shape, according to variables (X1) and (X2), is varied, the new CAD file is automatically redrawn with regard to the change of the design variables. The process of automatic mesh generation follows. In this

Table 2. The Level of Design Variables.

\begin{tabular}{cccccc}
\hline \multirow{2}{*}{$\begin{array}{c}\text { Design } \\
\text { Variables }\end{array}$} & \multicolumn{5}{c}{ The level of design variables } \\
\cline { 2 - 6 } & -2 & -1 & 0 & 1 & 2 \\
\hline W1 & 8.009 & 7.759 & 6.509 & 5.259 & 5.009 \\
W2 & 5.009 & 5.259 & 6.509 & 7.759 & 8.009 \\
\hline
\end{tabular}

Table 3. The Level of Design Variables for Edge.

\begin{tabular}{cccccc}
\hline \hline \multirow{2}{*}{$\begin{array}{c}\text { Design } \\
\text { Variables }\end{array}$} & \multicolumn{5}{c}{ The level of design variables } \\
\cline { 2 - 6 } & -4.2426 & -3 & 0 & 3 & 4.2426 \\
\hline P1 & -9.502 & -8.259 & -5.259 & -2.259 & 1.017 \\
P2 & 1.017 & 2.259 & 5.259 & 8.259 & 9.502 \\
\hline
\end{tabular}

way, this procedure goes on until $\mathrm{N}$.

Step 8: The response surface model is created by data obtained from FEA according to an established range.

Therefore, it is possible to determine the optimum torque density.

The RSM seeks to find the relationship between design variable and response through statistical fitting methods, which are based on the observed data from system [5].

\section{Result And Discussion}

FEA-based simulation is used to obtain the responses with respect to the CCD experimental design in TABLE 1, 2, 3, 4. Fig. 4-6 show configuration and torque characteristic of the initial model, only optimized pole width model, and optimized pole width \& edge model, respectively.

As shown in Fig. 5, whereas torque ripples of FSM of optimized width is improved and has a lower value than those of the initial model, the reverse torque value remained.

When W1 is $5.259 \mathrm{~mm}, \mathrm{~W} 2$ is $5.259 \mathrm{~mm}, \mathrm{P} 1$ is $0 \mathrm{~mm}(\operatorname{arc})$,

Table 4. Experimental Results Using Central Composite Design for Pole Width.

\begin{tabular}{ccccc}
\hline \hline $\begin{array}{c}\text { H(Number of } \\
\text { Variable) }\end{array}$ & X1(W1) & X2(W2) & Torque & $\mathrm{T}_{\text {peak }} / \mathrm{T}_{\text {ave }}$ \\
\hline 1 & 6.509 & 6.509 & 0.097 & 4.437 \\
2 & 6.509 & 7.759 & 0.100 & 4.403 \\
3 & 6.509 & 8.009 & 0.102 & 4.392 \\
$\ldots$ & $\ldots$ & $\ldots$ & $\ldots$ & $\ldots$ \\
9 & 5.259 & 5.259 & 0.1417 & 3.148 \\
10 & 5.259 & 5.009 & 0.139 & 3.146 \\
11 & 5.009 & 6.509 & 0.057 & 7.609 \\
$\ldots$ & $\ldots$ & $\ldots$ & $\ldots$ & $\ldots$ \\
23 & 8.009 & 8.009 & 0.037 & 12.130 \\
24 & 8.009 & 5.259 & 0.050 & 8.599 \\
25 & 8.009 & 5.009 & 0.049 & 8.581 \\
\hline
\end{tabular}

Table 5. Experimental Results Using Central Composite Design for Edge.

\begin{tabular}{ccccc}
\hline $\begin{array}{c}\text { H(Number of } \\
\text { Variable) }\end{array}$ & X1(P1) & X2(P2) & Torque & $\mathrm{T}_{\text {peak }} / \mathrm{T}_{\text {ave }}$ \\
\hline 1 & 3.0 & 3.0 & 0.135 & 3.531 \\
2 & 4.2426 & 0 & 0.108 & 4.402 \\
3 & 3.0 & -3.0 & 0.129 & 3.817 \\
$\ldots$ & $\ldots$ & $\ldots$ & $\ldots$ & $\ldots$ \\
10 & 0 & -4.2426 & 0.140 & 2.944 \\
11 & -4.2426 & 0 & 0.025 & 17.05 \\
$\ldots$ & $\ldots$ & $\ldots$ & $\ldots$ & $\ldots$ \\
23 & 0 & 4.2426 & 0.143 & 3.413 \\
24 & -3 & -3 & 0.074 & 5.145 \\
25 & -3 & 3 & 0.067 & 6.921 \\
\hline
\end{tabular}




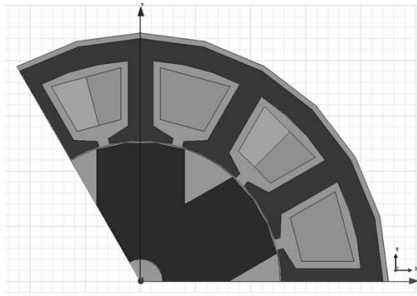

(a) Configuration

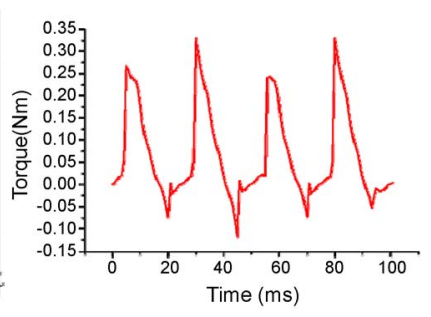

(b) Torque characteristics
Fig. 4. Configuration and torque characteristic of initial model.

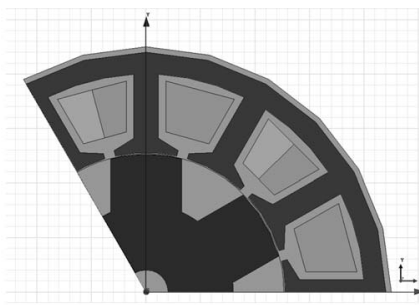

(a) Configuration

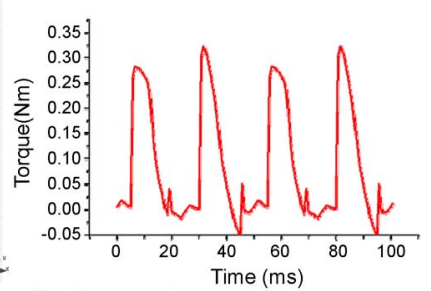

(b) Torque characteristics
Fig. 5. Configuration and torque characteristic of optimized pole width.

and $\mathrm{P} 2$ is $-4.2426 \mathrm{~mm}(\operatorname{arc})$ through edge optimization, the torque ripple of the FSM is minimized and the reverse torque is removed, as shown in Fig. 6.

The average torque of the initial model is 0.0639 [Nm], while the average torque of the optimized model is 0.1341 $[\mathrm{Nm}]$. As a result, torque characteristics are considerably improved.

\section{Conclusion}

A method of design related to the torque density and ripple of a flux switching motor with varying rotor shape

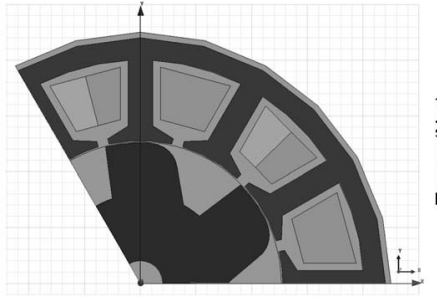

(a) Configuration

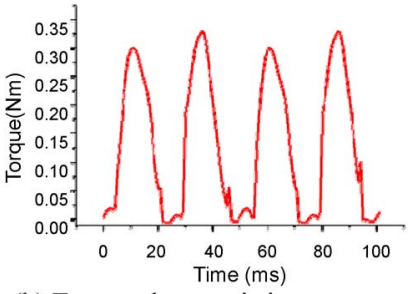

(b) Torque characteristics
Fig. 6. Configuration \& torque characteristic of optimized pole width and edge.

has been proposed.

For rapid design, an automatic pre-process that includes an automatic ACAD file drawing and mesh generation which varies according to the rotor shape variations has been developed.

Starting from an existing design, the best design solution is selected and the appropriateness of RSM in the machine's optimization method is verified by solution of the optimized design of a flux switching motor.

\section{References}

[1] J. M. Park, S. I. Kim, J. P. Hong, and J. H. Lee, IEEE Trans. Magn. 42, 3479 (2006).

[2] Y. C. Choi, J. H. Lee, and J. P. Hong. J. Appl. Phys. 103, 07F133 (2008).

[3] Y. C. Choi, H. S. Kim, and J. H. Lee, IEEE Trans. Magn. 44, 4135 (2008).

[4] C. Pollock, M. A. Wallace, and J. D. Wale, IEEE Industry Applications Conference, Vol. 3, 1980 (1999).

[5] K. F. Raby, Students' Quarterly Journal 21, 15 (1950). 